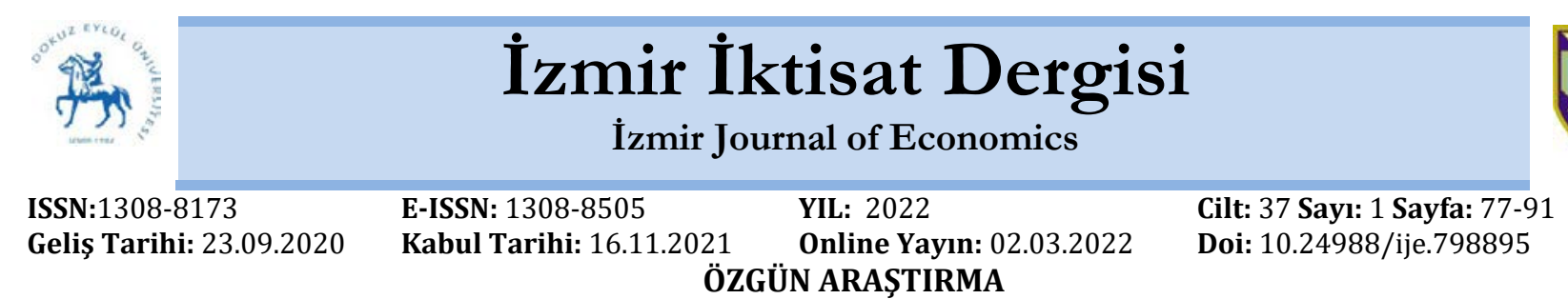

\title{
Farklılaştırılmış Entegrasyon Modelleri ve Avrupa Birliği Vatandaşları Üzerindeki Etkileri
}

\section{Özlem SEFER ${ }^{1}$}

\section{Özet}

Farklılaştırılmış entegrasyon, son yıllarda Avrupa Birliği (AB) gündeminin en temel meselelerden biri haline gelmiştir. 'Tek bedenin herkese uyması' (one-size-fits-all) prensibinin bazı durumlarda yetersiz kalması özellikle genişleme ve derinleşme adımlarıyla birlikte daha belirgin bir hal almıştır. Bu yüzden, farklılaştırılmış entegrasyon düşüncesi çerçevesinde Birlik için yeni bir model arayışı kaçınılmaz olmuştur. Bu makalede, Juncker Komisyonu döneminde (2014-2019) 'Avrupa'nın Geleceği Üzerine' hazırlanmış olan Beyaz Kitap'ta yer alan beş farklı senaryo, farklılaştırılmış entegrasyon modelleriyle birlikte düşünülerek incelenecek ve söz konusu senaryo ve modellerin AB vatandaşlarına potansiyel etkileri ele alınacaktır.

Anahtar kelimeler: Farklılaştırılmış entegrasyon, AB vatandaşlı̆̆ı, Avrupa'nın geleceği üzerine beyaz kitap Jel kodu: F5, D7, D8

\section{Models of Differentiated Integration and Their Effects On European Union Citizens}

\begin{abstract}
Differentiated integration has become one of the main concepts of the European Union (EU) agenda in recent years. The inadequacy of the principle of 'one-size-fits-all' in certain cases has become apparent especially with the widening and deepening steps. Therefore, the search for a new model for the Union within the framework of the idea of differentiated integration has been inevitable. In this article, five different scenarios in White Paper on the Future of Europe that released in The Juncker Commission's term (2014-2019) will be analyzed in relation to the models of differentiated integration and the potential effects of these scenarios and models on EU citizens will be examined.
\end{abstract}

Keywords: Differentiated integration, EU citizenship, White paper on the future of Europe.

Jel classification: F5, D7, D8

ATIF ÖNERİSİ (APA): Sefer, Ö. (2022). Farklılaştırılmış Entegrasyon Modelleri ve Avrupa Birliği Vatandaşları Üzerindeki Etkileri. İzmir İktisat Dergisi, 37(1). 77-91. Doi: 10.24988/ije.798895

${ }^{1}$ Dr., Bilkent Üniversitesi Siyaset Bilimi ve Kamu Yönetimi Bölümü, E-mail: ozlem.sefer@bilkent.edu.tr, ORCID: 0000-0002-7730-6556. 


\section{GíRiș}

Farklılaştırılmıș entegrasyon, son yıllarda Avrupa Birliği (AB) literatüründe sıkça ele alınan ve hem teorik hem de pratik anlamda gerek birbirinden farklı model önerileri gerek bu modellerin uygulanmasının olası sonuçları çerçevesinde tartışılmakta olan bir kavramdır. Özellikle, AB'nin ekonomik krizle mücadelesi, 2016 senesinde yapılan referandum sonrası Birleşik Krallık'ın AB'den ayrılma kararı (Brexit) ve bu kararın uygulanmasıyla ilgili süregelen tartışmalar, mülteci krizi ve bu konuda üye ülkelerin birbirlerinden farklılık gösteren tutumları, farklılaștırılmıș entegrasyon önerilerini gündemde tutan konu başlıklarındandır. AB'nin geleceği için birden fazla farklılaştırılmış entegrasyon önerisi bulunmaktadır. Bu önerilerden bazıları; iki vitesli Avrupa, değișken geometrili Avrupa, çok vitesli Avrupa, güçlendirilmiş işbirliği ve a la carte Avrupa'dır. Ancak söz konusu kavramlar, AB için yeni bir yol haritası belirlemek ve kimi alanlarda yeni düzenlemeler yapmak adına önemli oldukları kadar tartışmaları da beraberinde getiren kavramlardır. $\mathrm{Bu}$ çalışmada farklılaştırılmış entegrasyon modelleri, Birlik vatandaşlarının AB hakkında sahip oldukları algıya ve AB'ye yaklaşımlarına doğrudan ve dolaylı etkileri göz önüne alınarak incelenecektir. Çalışmanın ilk bölümünde, farklılaştırılmış entegrasyon üzerine geliştirilmiş modeller olan çok vitesli Avrupa, değişken geometrili Avrupa, a la carte Avrupa, güçlendirilmiş işbirliği ve iki vitesli Avrupa üzerinde durulacaktır. İkinci bölümde Avrupa Komisyonu'nun Spitzenkandidaten uygulamasıyla -AB vatandaşlarının aynı zamanda Avrupa Komisyonu Başkanı'nın seçiminde de rol oynadıkları bir uygulama- seçilen ilk Komisyon başkanı olan Jean-Claude Juncker başkanlığı döneminde hazırlanan Beyaz Kitap'tan yola çıkarak, Avrupa'nın geleceği üzerine önerilen beş farklı senaryo ele alınacaktır. $\mathrm{Bu}$ beș farklı senaryonun, farklılaştırılmıș entegrasyon modellerine ișaret ettiği göz önüne alınarak, üçüncü ve son bölümde ise, Juncker Komisyonu'nun hazırlamış olduğu beş farklı senaryo, Birlik vatandaşlarına potansiyel etkileri ve vatandaşların bu farklı entegrasyon modellerine yaklaşımları çerçevesinde incelenecektir. Özellikle söz konusu modellerin bir kısmında yer alan, Birlik üyesi ülkelerin, farklı hızlarda hareket etmesini öngören yaklaşımların, üye ülke vatandaşları tarafından nasıl karşılanacağı üzerinde durulacaktır. $A B$ vatandaşlarının, gelecekte nasıl bir AB görmek istedikleri, farklılaștırılmış entegrasyon modellerinden ve bununla bağlantılı olarak Avrupa'nın geleceği üzerine sunulan beş farklı senaryodan hangisine daha olumlu yaklaşabilecekleri ise EUpinions ve Eurobarometer anket sonuçlarından faydalanarak tartışılacaktır.

\section{AVRUPA BIRLIIĞI'NİN GELECEĞİ İÇİN ÖNERILER: FARKLILAŞTIRILMIŞ ENTEGRASYON MODELLERI}

Birlik henüz $\mathrm{AB}$ adını almadığı zamanlarda, entegrasyon sürecinin ilk adımları atılırken, alınan kararların, yapılan düzenlemelerin ve ortak politikaların her üye ülkede aynı şekilde uygulanacağı düşüncesiyle yola çıkılmıştır. 1950'lerde karar-verme mekanizması, tek bir kararın her üye ülkeye uyacağı düşüncesiyle şekillenmiştir (Piris, 2012: 54). Ancak zaman içinde gerek üye ülke sayısının artması gerek derinleşme yolundaki adımlar, kimi farklılıkları da beraberinde getirmiștir. Farklılaștırılmış entegrasyon düşüncesi de Avrupa entegrasyonunun üniter olma (unitary) prensibinin sürdürülebilir olmayacağının anlaşılmasıyla birlikte ortaya çıkmıştır (Dyson ve Sepos, 2010: 10). 'Tek bedenin herkese uyması' düşüncesi ve uygulamasının, genişleme süreci devam eden $\mathrm{AB}$ için uygunluğunun tartışılır hale gelmesi, entegrasyon sürecinin devam edebilmesi için farklı önerileri beraberinde getirmiştir. 1975 senesinde yayımlanan Tindemans Raporu'yla, konuyla ilgili noktalara değinilmiş ancak AB Antlaşmaları'nda farklılaştırılmış entegrasyon ilk kez 1990'larda ele alınmıştır. 1997 senesinde imzalanan Amsterdam Antlaşması, farklılaştırılmış entegrasyon kavramının resmi olarak görüldügü antlaşma olup, Nice Antlaşması'nda da bu konuyla ilgili düzenlemeler için yol açıldığı görülmektedir (De Neve, 2007: 505-506). De Neve, Amsterdam Antlaşması'nda 'daha yakın işbirliği', Nice Antlaşması'nda 'güçlendirilmiş işbirliği' ve AB Anayasal 
Antlaşma Taslağı'nda ise özellikle Ortak Güvenlik ve Savunma Politikası düşünülerek ele alınmış olan 'yapısal işbirliği' vurgularının varlığından söz etmektedir (De Neve, 2007: 506).

Farklılaştırılmış entegrasyon, AB'nin dağılma olasılığına karşı, olumlu bir anlam taşımaktadır (Schramm, 2019: 3). Özellikle son yıllarda AB'nin ekonomik ve politik anlamda yaşadığı sıkıntılar, AB'nin dağılması üzerine düşünce ve tartışmaları, muhtemel kimi senaryoları da beraberinde getirmektedir. Birleşik Krallık'ın AB'den ayrılma talebi, Yunanistan, İtalya, İspanya gibi AB üyesi ülkelerin yaşadıkları ekonomik kriz, Birlik'in işleyişini ve Birlik'in geleceğini tartışmaya açık hale getirmiş, söz konusu krizler, AB'nin dağılması yönündeki senaryoları da gündeme getirmiştir. Farklılaştırılmış entegrasyon, AB'nin entegrasyon süreci için bir 'kurtarıcı' görevi üstlenip, entegrasyonun sürdürülmesine hizmet etme potansiyeli taşımaktadır (Dyson ve Sepos, 2010: 13). Farklılaştırma; üye ülkelerin, ortak politika alanlarına saygı duyma prensibi esas alınarak, farklı haklara ve yükümlülüklere sahip olmasıyla mümkündür (Kölliker, 2001: 127).

Stubb; çok vitesli Avrupa, a la carte Avrupa ve değişken geometrili Avrupa'yı üç temel başlık olarak ele almış, iki vitesli Avrupa'yı, çok vitesli Avrupa'nın, dışta kalma hakkını (opt-out) ise a la carte Avrupa'nın alt kategorileri olarak incelemiștir (Stubb, 1996: 285). Maastricht Antlaşması'yla birlikte gelen 'dışta kalma hakkı'yla birlikte Birleşik Krallık, Danimarka, İsveç gibi ülkeler bazı alanlarda bu haktan faydalanmıştır. Maastricht Antlașması'yla uygulanması mümkün hale gelen bu hak, üye ülkeler arasında bir çeşit farklılık yaratmıştır. Maastricht Antlaşması'na eklenen Protokol sayesinde Danimarka ve Birleşik Krallık, opt-out sahibi olmuştur. Danimarka, 1992 senesinde Maastricht Antlaşması'nın kabulüyle ilgili referanduma gitme kararı almıştır. Maastricht Antlaşması'nın kabul edilmemesi yönündeki kampanyaların en temel argümanlarından birisi Topluluk içinde Fransa, Almanya gibi büyük devletlerin baskın olacağı ve küçük ülkelerin bu şekilde kontrol sahibi olamayacakları üzerinedir ("Denmark rejects the Maastricht Treaty," 1992). Sonuç olarak Maastricht Antlaşması'nın, Danimarka'da yapılmış olan referandumdan çıkan 'hayır' oyuyla yeniden düzenlenmesi gerekmiştir. Birleşik Krallık ve Danimarka, Maastricht Antlaşması'na eklenen Protokol'lerle bazı alanlardaki ortaklıklara katılmamıștır. Örneğin, Danimarka'nın Ekonomik ve Parasal Birlik'in üçüncü ve son aşamasına dahil olmaması ve kendi para birimini kullanmaya devam etmesi söz konusu Protokol'le garanti altına alınmıştır. Opt-out sahibi olan ülkeler, zamandan bağımsız olarak bu hakka sahip oldukları için, hiçbir zaman ya da hiçbir dönemde bu alanlarda AB'yle ortaklığa gitmeleri zorunlu olmayacak, bu alanların dışında yer alacaklardır.

Piris, Danimarka ve Birleşik Krallık'tan örnek vererek, söz konusu ülkelerin AB üyesi olmalarına rağmen bazı alanlarda diğer üye ülkelerle aynı 'vites'te hareket etmediklerini söylemektedir (Piris, 2012: 77). Bu durumda AB, Avro ve Schengen uygulamasındaki farklar göz önüne alınarak düşünüldüğünde zaten iki vitesli bir şekilde hareket etmektedir (Piris, 2012: 62) İki vitesli ya da çok vitesli Avrupa kavramları çerçevesinde ele alındığında, bu iki kavramın günümüzdeki AB'nin yakınında duran kavramlar olduğu söylenebilir (Holzinger ve Schimmelfennig, 2012: 294). A la carte Avrupa, iki vitesli Avrupa'yla aynı anlamı taşımamaktadır. İki vitesli Avrupa, a la carte Avrupa mantığından farklı olarak, AB'nin ortak alanlarında, politikalarında kalıcı bir muafiyet öngörmemektedir. Bazı üye ülkeler kimi politikalara daha kolay uyum sağlama potansiyeline sahipken, bazıları bu uyumu sağlamak için kimi düzenlemelere ihtiyaç duyabilmektedir. Bunlar, söz konusu alanın niteliğine bağlı olarak ekonomik, siyasi ya da sosyal alanda yapılması gereken düzenlemeler olabilmektedir. Bu durumda olan üye ülkeler, kendi 'vites'lerinde yol almakta olsalar da, söz konusu farklılık geçici olduğundan daha kolay uyum sağlama kapasitesine sahip ülkelerle aynı hedefte buluşmaları esastır (Piris, 2012: 7). Bir üye ülkenin diğer üye ülkelerden farklı olarak muaf olduğu herhangi bir alan bulunmamakta ancak uygulama her üye ülkede aynı zamanda olmamakta ve uygulanacak politika bütün üye ülkelerde aynı anda yürürlüğe girmemektedir. 
İki vitesli Avrupa fikrinin ele alındığı ilk belge 1975 senesinde yayımlanan Tindemans Raporu'dur (Teasdale ve Bainbridge, 2012: 814). Hedeflenen ve öngörülen modelin a la carte bir Avrupa olmadığı, her üye ülkenin nihai hedef olarak ortak politikaları uygulamayı taahhüt ederek, belirlenen farklı zaman çizelgeleriyle bunlara uyum sağlamaları gerektiği vurgulanmaktadır ("Report on European Union," 1975). Söz konusu dönemde bütün üye ülkelerin (bu dönemde Avrupa Ekonomik Topluluğu dokuz üyelidir) her aşamaya aynı zamanda adapte olması mümkün olmadığından, Leo Tindemans ekonomik ve finansal farklılıklar gereği tek tip bir ilerleme için israrcı olmanın anlamsızlığına vurgu yapmaktadır ("Report on European Union," 1975). İki vitesli Avrupa, üye ülkelere, politikalara dahil olma konusunda zaman kısıtlaması getirmeyerek, esneklik sağlaması bakımından bir kolaylık gibi görünse de, sorunlu kimi noktalar da barındırmaktadır. Bunlardan bir tanesi, bu uygulamanın $\mathrm{AB}$ vatandaşlarında yaratacağı algıyla ve aidiyet konusuyla ilgilidir. AB içinde bazı ülkelerin daha hızlı, bazılarının ise daha yavaş bir şekilde yol alması ve bu durumun Birlik vatandaşları arasında bir ayrım yaratma olasılığı, iki vitesli Avrupa tartışmalarındaki önemli noktalardan biridir. 'Íki vitesli Avrupa'nın 'iki sınıflı Avrupa' gibi algılanması, bu tip bir sorunun sebeplerinden olup, söz konusu düşüncenin temelinde bazı AB üye ülkelerinin daha yakın bir işbirliği içinde olmaları, diğer üye ülkeleri bu işbirliğine dahil etmemeleri, dışarıda bırakmaları vardır (Piris, 2012: 7). AB üye ülkeleri arasında böyle bir ayrımın meydana geleceğini düşünen vatandaşların, bu tip bir entegrasyon önerisine sıcak bakmayacakları söylenebilir. 'İki sınıflı Avrupa' düşüncesinin, $A B$ vatandaşları arasında 'birinci-sınıf' 'ikinci-sınıf' ayrımı getirmesi, karar-verme mekanizmalarında vatandaşların yer almaları için çeşitli düzenlemeler yapan, yenilikler getiren Birlik'in entegrasyon adımlarını olumsuz etkileyecektir. Birlik içinde entegrasyona yeni bir yön vermek, bir ivme kazandırmaya çalışmak hedeflenirken, 'ikinci sınıf' algısının oluşmaması da sağlanmalıdır.

Çok vitesli Avrupa fikri, iki vitesli Avrupa düşüncesine benzerlik göstermekte ancak uyumlaştırma adımlarının iki ayrı hızda olmasını değil, her ülkenin düzenlemelerini kendi hızına göre yapmasını öngörmektedir. Birlik içindeki ilerlemesini, ortak hedefler çerçevesinde, daha hızlı ve istekli sürdüren üye ülkelerin yola devam etmesini, diğer üye ülkelerin de kendi hızlarına göre onları takip etmesini önermektedir ("Multi-speed Europe," t.y.). Çok vitesli Avrupa, iki vitesli Avrupa'ya göre daha geniş bir hareket alanı sağlamakta ve Birlik içinde daha fazla 'farklılık' anlamına gelmektedir. Her üye ülke, AB içinde hedeflenen amaçlara, ortak politikalara, kendi ilerleme hızına göre adapte olabilecektir. Üye ülkeler aynı politikaları uygulayacak, ancak bu politikalara uyumlarını eşzamanlı olarak değil, farklı zamanlarda sağlayacaktır (Stubb, 1996: 287). De Vries, çok vitesli Avrupa'nın hangi ülkelerin 'merkez'e, hangilerinin 'çevre’ye ait olduğuyla ilgili tartışmalara sebep olacağını ve bu durumun böyle bir proje için kamunun onay düzeyini arttırmaktan çok azaltmaya sebep olacağını vurgulamaktadır (De Vries, 2018: 218). Stubb'ın sınıflandırmasından yola çıkılacak olursa, iki vitesli Avrupa da çok vitesli Avrupa'nın alt kategorisi olduğundan, aynı durum ve hatta belki daha karmaşık hali, çok vitesli Avrupa için de geçerli olmakta ve benzer riskler taşımaktadır.

Değişken geometrili Avrupa, farklılaştırılmış entegrasyon modellerinden bir diğeridir. Bu modelde, iki vitesli ve çok vitesli Avrupa gibi üye ülkelerde farklı hızlarda ortak politikaların uygulanmasının mümkün kılınmasından daha farklı bir öneri vardır. Söz konusu modelin çok vitesli Avrupa ve $a$ la carte Avrupa ortasında bir noktada durduğu söylenebilir (Stubb, 1996: 289). “AB'nin bütünleşme yeteneği açısından aralarında sürekli bir ayrımın bulunduğu iki grup ülke belirlenmiştir: İlk grup bütünleşmiş ülkeler, ikinci grup ise diğer üyelerdir" (“AB Kavramları Sözlügüu," t.y.). Bu modelde, üye ülkeler arasındaki farklılıkların aşılamaz olduğunu ve bundan dolayı gelişmiş çekirdek ülkelerle daha az gelişmiş ülkelerin entegrasyonunun farklı şekilde olması gerektiğinin altı çizilmektedir (Stubb, 1996: 285). Farklı zamanlarda aynı politikaların uygulanmasından değil, birlik içinde birkaç farklı düzenleme yapılmasından söz edilmektedir. Bu durum, $\mathrm{AB}$ içinde merkez ülke-çevre ülke algısı 
oluşma riskini, kimi üye ülkeleri birbirlerinden ve $A B$ 'den uzaklaştırma tehlikesini de barındırmaktadır.

Güçlendirilmiş işbirliği modelinin temelinde, AB'den gelen bir önerinin, buna olumlu bakmayan bir ya da birden çok üye ülke tarafından engellenmesinin önüne geçme amacı olduğu görülmektedir ("Enhanced Cooperation," t.y.) En az dokuz üye ülkenin AB'nin bazı alanlarında daha derin bir ortaklık yaratmasına olanak sağlayan ve bu ortaklığın içinde yer almak istemeyen ülkelerin söz konusu ortaklığa katılmamasını mümkün kılan bir prosedürden söz edilmektedir ("Enhanced Cooperation," t.y.) Bu modelde, hem AB'deki derinleşme adımlarını daha ileriye götürmek isteyen ülkeler arasındaki ortak alanları ve yakınlığı arttırma, hem de AB içinde daha sınırlı alanlarda ortaklık öngören ülkelerin bu ortaklıkları 'engellemesinin' ya da bazı durumlarda 'yavaşlatmasının' önüne geçme amacından söz edilebilir. Kuşkusuz, her üye ülke ekonomik, politik ve sosyal anlamda aynı değildir. Temel olarak AB; liberal demokrasi, açık pazar gibi ortak değerleri benimsemiş olan ülkelerden oluşmuş olsa da, $\mathrm{AB}$ ülkeleri, pek çok anlamda birbirlerinden farklılık göstermektedir. Bu durumun yanı sıra, her üye ülkede Birlik vatandaşlarının, AB'ye karşı birbirlerinden farklı yaklaşımlarının olduğu da görülmektedir. Ulusal siyasetlerin de etkisiyle, bazı üye ülke vatandaşlarının daha pro-Avrupacı, bazılarının ise daha Avrupa-şüphecisi bir görüşe sahip olduğu açıktır. $\mathrm{Bu}$ durum göz önüne alındığında ise, $A B$ 'de daha yakın işbirliğini savunan ülkelerin güçlendirilmiş işbirliği gibi bir modele sıcak bakma olasılığının yüksek olacağı söylenebilir. Ancak tıpkı diğer modellerde olduğu gibi, bu modelin de $\mathrm{AB}$ vatandaşları arasında, üye ülkeler arasında bir çeşit ayrım yaratılması, Birlik içinde daha küçük birliklerin oluşmasıyla ilgili bir algıya sebep olabileceği gibi, merkez Avrupa ülkeleri-çevre Avrupa ülkeleri ayrımının güçlenmesine de yol açabilecektir.

\section{AVRUPA'NIN GELECEĞİ ÜZERINE: JUNCKER KOMISYONU SENARYOLARI}

2017 senesinde Avrupa Komisyonu'nun ‘Avrupa'nın Geleceği’ ana temasıyla hazırladığı Beyaz Kitap, farklılaştırılmış entegrasyon önerileriyle beş farklı senaryo ortaya koymuştur ("White Paper on the Future of Europe," 2017). Juncker Komisyonu, Komisyon Başkanı'nın seçilme biçimi açısından farklı bir yere sahiptir. 2019 Avrupa Parlamentosu seçimlerinden bir önceki seçim olan 2014 seçimlerinde; demokrasi, şeffaflık, meşruiyet gibi Birlik içindeki tartışmalı konular çerçevesinde anlamlı düzenlemeler yapıldığı görülmüştür. 2014 senesinde Avrupa Komisyonu Başkanı ilk kez Spitzenkandidaten uygulamasıyla seçilmiş ve bu Komisyon'un Başkanı Jean-Claude Juncker olmuştur. Bu uygulama, dolaylı bir şekilde de olsa AB seçmenlerinin Avrupa Komisyonu Başkanı'nın seçiminde yer almalarına olanak sağlamıştır ("Democracy on the Move," 2018). AB vatandaşlarını temsil etmekte olan ve üyeleri doğrudan seçimle belirlenen bu kurumun, Avrupa Komisyonu Başkanı'nın seçiminde söz konusu uygulamayla yer alması anlamlıdır. Birlik vatandaşları \%49 oranında, 2019 seçimlerinde oy kullanmaları için kendilerine motivasyon sağlayan etken olarak Spitzenkandidaten uygulamasından söz etmişlerdir ("Democracy on the Move," 2018). 2019 Avrupa Parlamentosu seçimlerinde katılım oranının önceki seçimlere oranla yüksek olduğu görülse de, Spitzenkandidaten uygulamasının bu seçimde uygulanmadığı görülmüş, bu da söz konusu uygulamanın devamlılığı ve sürdürülebilirliği konusunda soru işareti oluşturmuştur. Avrupa Komisyonu'nun Spitzenkandidaten uygulamasıyla seçilen başkanı Jean-Claude Juncker döneminde hazırlanan Beyaz Kitap, yalnızca Avrupa'nın geleceği üzerine ortaya koymuş olduğu senaryolarla değil, aynı zamanda 2019 Avrupa Parlamentosu seçimlerine kadar hem ulusal yetkililerin hem de AB yetkililerinin katılımıyla sürdürülmüş olan tartışmalar açısından da anlamlıdır.

Avrupa Komisyonu'nun hazırlamış olduğu Beyaz Kitap, AB’nin geleceği için uygulanabilir beş farklı senaryoya değinmektedir. 2016 senesinde yapılan referandum sonrası AB'den ayrılma kararı alan Birleşik Krallık’ın artık Birlik üyesi olmayacağı da göz önüne alınarak, yirmi yedi üyeli AB için beş gelecek senaryosu ele alınmıștır. 2025 senesindeki AB'nin nasıl bir Birlik olacağı ya da olması 
gerektiği üzerinde durulmuştur. Özellikle Birlik'in son yıllarda yaşadığı gerek ekonomik gerek siyasi alandaki krizler, yeni bir yol haritası belirlenmesinin gerekliliğini ortaya koymuștur. Daha önce de söz edildiği gibi, Birlik'in ilk zamanlarında uygulanması öngörülen 'tek bedenin herkese uyması' prensibi, günümüzdeki $\mathrm{AB}$ için uygulanması oldukça güç bir hal almaya başlamıştır. Birleşik Krallık referandumundan Birlik'ten ayrılma kararının çıkması, Birlik'in dağılması üzerine iddiaları ve öngörüleri de arttırmıştır. Juncker Komisyonu da farklı senaryolar üzerinde durarak, Avrupa'nın geleceğinin nasıl şekillenebileceğini ele almıştır.

Söz konusu senaryolardan birincisi, AB'nin yoluna aynı şekilde devam etmesi yönündedir. Bu senaryoda, AB'nin mevcut reform gündemini iyileștirip, geliștirerek uygulaması öngörülmektedir ("White Paper on the Future of Europe," 2017). Bu senaryo, AB'nin işleyişi, mevcut politikaları ve uygulamaları açısından herhangi bir sıkıntısının olmadığına işaret etmektedir. Bu senaryodan yola çıkarak söylenecek olursa, AB'nin farklılaştırılmış bir entegrasyona gitmesi çok anlamlı ve gerekli değildir. Ĕger günümüzdeki $A B^{\prime}$ 'de 'tek bedenin herkese uyması' uygulamasının esas olduğu ve $A B$ 'nin bu prensip çerçevesinde yola devam ettiği kabul edilecek olursa, bu senaryoda, her üye ülkede aynı politikaların aynı zamanda uygulanması prensibinin sürdürülmesinden söz edilmektedir. Ancak eğer, Holzinger ve Schimmelfennig'in (Holzinger ve Schimmelfennig, 2012: 294) sözünü ettiği ve Piris'in (Piris, 2012: 62) Avro ve Schengen alanlarını göz önüne alarak vurgu yaptı̆̆ gibi, günümüzdeki $\mathrm{AB}$ 'nin farklı viteslerde hareket ettiği fikri kabul edilecek olursa, bu durum halihazırda farklılaștırılmış entegrasyon modellerinden birinin AB'de uygulanmakta olduğuna işaret etmektedir. Uyum süreci, ülkelerin geçiş süreçleri gibi durumlar da göz önüne alındığında, aynı politikalar her üye ülkede aynı zamanda uygulanamamaktadır. Eğer AB'nin geleceği için ilk senaryo öngörülüyorsa ve mevcut durumda çok vitesli Avrupa modelinin uygulandığı varsayllıyorsa, bu düşünceden, çok vitesli Avrupa'ya devam edilmesi anlamı çıkmaktadır. Özetle, birinci senaryoda mevcut durumun korunması esas olup, birkaç küçük değişiklikle, 2025'teki $\mathrm{AB}$, günümüzdeki $\mathrm{AB}$ 'den çok farklı olmayan bir işleyişe sahip olacaktır.

İkinci senaryo, yalnızca Tek Pazar üzerine yoğunlaşmış bir Birlik öngörmektedir. Bu senaryoda; göç, güvenlik, savunma gibi alanlardaki ortaklıkların güçlendirilmesi yerine Tek Pazar'ın güçlendirilmesi ve derinleșme adımlarının bu yönde atılması fikri esas alınmıștır ("White Paper on the Future of Europe,” 2017). "1986 yılında imzalanan ve 1987 yılında yürürlüğe giren Avrupa Tek Senedi ile 1992 yılında Tek Pazar'ın bütün yönleriyle tamamlanması karara bağlanmıştır” (Olcay, 2007: 188). Beyaz Kitap'ta düzenlenen ikinci senaryoda, AB'nin işleyişindeki raison d'etre Tek Pazar olarak belirlenmiștir ("White Paper on the Future of Europe," 2017). Ekonomik alandaki ortaklıklar kuşkusuz AB'nin varlığı ve geleceği için son derece önemlidir. Ancak ekonomik alandaki birliğini, siyasi ve sosyal alana da taşımış olan bir birliğin, bu alandaki ortaklıkları devam ettirmeden yoluna devam etme çabası son derece sınırlı bir birlik anlayışını da beraberinde getirecektir. Malların, kişilerin ve hizmetlerin serbest dolaşımının da esas olduğu Tek Pazar mantığında, bu alanlarda da yeni düzenlemeler yapılması gerekecektir. $A B$ vatandaşlarının hakları anlamında sınırlamalar meydana gelebilecek, ulusal sınırlarda kontroller, güvenlik ve göçle ilgili konular artık bir ortaklığın parçası olmayacağından artacak, işçilerin serbest dolaşımı gibi konuların yeniden düzenlenmesine ihtiyaç duyulacaktır ("White Paper on the Future of Europe," 2017). Bu durum, hem Birlik vatandaşlarının günlük hayatlarını etkileyecek, hem de AB'nin pek çok alanda revizyona gitmesi anlamına gelecektir. Yalnızca Tek Pazar üzerinden sürdürülecek bir ortaklık, özellikle AB'yle ilişkilerde 'derinlik' düşüncesiyle de çelişmektedir.

Üçüncü senaryo, AB'yle daha fazla alanda ortaklık ve işbirliği isteğinde olan ülkelere bir çeşit yol açmaktadır. Örneğin; vergilendirme ve sosyal konuları içeren alanlarda ya da güvenlik ve adalet alanlarında daha yakın bir işbirliğine olumlu bakan ülkeler bir araya gelerek, bu alanlarda birlikte yol almaya karar verebilmektedir ("White Paper on the Future of Europe," 2017). Kimi ülkeler, AB'yle 
daha fazla alanda işbirliği yapmak ve ortak politikalar uygulamak taraftarıyken, kimi ülkeler tam aksine, mümkün olduğu kadar az alanda ortaklık ve işbirliğini savunmaktadır. Bu durum, AB içinde derinleşme adımlarını doğrudan etkilemektedir. Üçüncü senaryo, farklılaștırılmış entegrasyon modellerinden olan güçlendirilmiş işbirliği önerisiyle paralellik göstermektedir. Bu modelin temel argümanında yer alan daha fazla işbirliğine olumlu bakan en az dokuz ülkenin bir araya gelmesi konusu, söz konusu senaryoda yer alan 'gönüllülerin koalisyonu' fikrini hatırlatmaktadır ("White Paper on the Future of Europe," 2017). Ancak pratiğe uygulanması öngörülen bu senaryonun ve farklılaştırılmış entegrasyon modelleri içinde yer alan güçlendirilmiş işbirliği fikrinin, beraberinde getirmesi muhtemel bazı risklerden de söz edilebilir. Bu risklerden bir tanesi hem AB üye ülkelerinin hem de $\mathrm{AB}$ vatandaşlarının birbirlerinden uzaklaşma olasılığıdır. Bazı $\mathrm{AB}$ üyelerinin bir ya da birden çok alanda daha fazla işbirliğine gitmeleri, 'birlik' olma düşüncesine ters düşecek ve $A B$ vatandaşları arasında da bir çeşit ayrıma sebep olabilecektir. Juncker, Beyaz Kitap'ta bütün AB üye ülkelerinin ve $\mathrm{AB}$ vatandaşlarının eșit bir şekilde muamele gördüğü bir Birlik isteğinin altını çizmektedir ("White Paper on the Future of Europe," 2017). Ancak bu düşünceyle, üçüncü senaryonun uygulamaya geçirilme olasılığı, tartışmaya açık bir duruma işaret etmektedir. Güçlendirilmiş işbirliği modelini hatırlatan üçüncü senaryo, özellikle 'birlik içinde birlik' yaratması açısından risk teşkil etmektedir. Ancak AB'nin geleceği, derinleşme adımlarının hız kazanması konusu göz önüne alındığında da barındırdığı riskler dışında uygulanması muhtemel bir senaryodur.

Değişken geometrili Avrupa fikri de, üçüncü senaryoda ele alınabilecek bir modeldir. Üye ülkeler arasında, 'merkez (ya da çekirdek) Avrupa ülkeleri' ve 'çevre Avrupa ülkeleri' algısının oluşması, AB'nin entegrasyon hedefine ulaşması yolunda zorlanması anlamına gelecektir. Merkez Avrupa ülkeleri olarak anılan ülkelerin, $\mathrm{AB}$ içinde ekonomik anlamda daha istikrarlı ve güçlü ülkeler olduğunu görmek mümkündür. Avusturya, Belçika, Finlandiya, Fransa, Almanya ve Hollanda'nın merkez Avrupa ülkeleri, çevre Avrupa ülkelerinin ise Yunanistan, İtalya, İrlanda, Portekiz ve İspanya olarak ele alındığı görülmektedir (Schmitter ve Lefkofridi, 2016: 10). Çevre ülkeler olarak ele alınan ülkelerin özellikle son yıllarda ekonomik krizle karşı karşıya kalmış olan ülkeler olduğu dikkat çekmektedir.

Dördüncü senaryo, daha az alanda işbirliğine gidilerek, bu alanlardaki politikaların daha verimli bir biçimde yürütülmesini öngörür. Örneğin, $A B$ hukukunda düzenlenmiş olan $A B$ vatandaşlarının hakları, işbirliğinin daha yoğun olması hedeflenen alanlarda güçlendirilecek, diğer alanlarda ise azaltılacaktır; buradaki esas zorluk bu alanların hangi alanlar olacağıyla ilgilidir ("White Paper on the Future of Europe," 2017). Bu senaryoyu gerçekleştirme hedefiyle yola çlkacak bir AB, öncelik vereceği alanları belirlerken son derece dikkatli seçimler yapmalıdır. Seçilen alanlar, hem üye ülkeleri hem de $\mathrm{AB}$ vatandaşlarını birbirlerine yakınlaştırabilecekken, tam tersi bir senaryoyla da karşı karşıya bırakabilecektir.

Beşinci ve son senaryo ise daha ileri bir işbirliği öngörmektedir. Tüm üye ülkelerin içinde olacağl şekilde, bütün alanlarda daha öncekinden çok daha güçlü bir işbirliğinin yaratılacağı bir birlik hedeflenmekte ve bu sayede $\mathrm{AB}$ düzeyindeki kararların çok daha hızlı alınacağı düşünülmektedir ("White Paper on the Future of Europe," 2017). Mali, sosyal ve vergilendirmeyle ilgili alanlarda oluşturulacak bir koordinasyon, AB'de ortak politikaların sayısının artacağının da göstergesidir ("White Paper on the Future of Europe," 2017). Bu senaryoda, AB'deki federal özelliklerin artacağı görülmektedir. Bu da, AB'nin federal bir birlik olmasına sıcak bakanlar için olumlu bir senaryodur. Beşinci senaryoda, söz konusu 'daha ileri işbirliği' önerisi, bütün üye ülkelerin içinde olması planlanan bir senaryo olarak ele alınmıştır.

Juncker'in Avrupa Komisyonu Başkanlığı döneminde hazırlanan Beyaz Kitap'ta yer alan Avrupa'nın geleceği için beş farklı senaryo, anlamlı argümanlar içerirken, kimi tartışmalı konuları da gündeme getirmektedir. Söz konusu senaryolar, Birlik vatandaşlarının AB’nin karar-alma sürecindeki yeri ve 
politika-yapım sürecine katılımıyla ilgili konularla da bağlantılı olduğundan, öne çıkarılacak senaryonun son derece özenli seçilmesi gerekmektedir.

\section{AVRUPA'NIN GELECEĞİ, FARKLILAŞTIRILMIȘ ENTEGRASYON VE AVRUPA BİRLİĞİ VATANDAŞLARININ YAKLAŞIMI}

Uzun bir süre, $A B$ vatandaşlarının entegrasyon süreciyle ilgilerinin olmadığı düşünülmüştür (Hobolt ve De Vries, 2016: 415). AB'nin gerek ulus-üstü gerek hükümetlerarası işleyen yapısından dolayı, Birlik vatandaşlarının karar-alma sürecinde yer almalarıyla ilgili düzenlemeler yapılması konusu üzerinde ciddi șekilde durulmamıștır. Ancak izin verici konsensus (permissive consensus)'un bir noktada yetersiz kaldığının anlaşılması ve entegrasyon sürecinin bu șekilde etkili bir biçimde yürümeyeceğinin fark edilmesiyle, $\mathrm{AB}$ vatandaşlarının da sürece dahil edilmesi söz konusu olmuştur. Özellikle 1993 tarihli Maastricht Antlaşması'nın kabul edilme sürecinde yaşanan sıkıntılar; alınan kararları, getirilen yenilikleri vatandaşların dolaylı olarak kabul ettikleri varsayımıyla hareket eden AB'de, işleyişin etkili ve yeterli olamadığını da ortaya koymuştur. Daha önce de söz edildiği gibi, Danimarka'nın Maastricht Antlaşması'nı kabul etmek istememesi ve yapılan referandumda 'hayır' oyunun çıkması, bazı politikaların dışında kalma hakkını beraberinde getirmiştir. Danimarka'nın, 'hayır' oylarıyla Maastricht Antlaşması'nı kabul etmemesi, AB vatandaşlarının desteğinin önemini bu noktadan sonra daha açık ve somut bir biçimde ortaya koymuştur. Esasında, AB'de yapılan referandumlar, $\mathrm{AB}$ vatandaşlarının karar-alma ve derinleşme süreçlerinde ne kadar etkili olabildiğini ve kimi zaman Birlik'te işleyişi ve hedefleri bile bütünüyle değiştirebildiğini göstermiştir. Bu çerçevede düşünüldüğünde, günümüzdeki $A B$ ve Avrupa'nın geleceği için önerilen fikirler, vatandaşlardan kopuk biçimde tartışılabilecek ve gerçekleştirilebilecek olmaktan uzaktır.

Avrupa Komisyonu, Avrupa Parlamentosu ve üye devletlerin 'Avrupa'nın Geleceği Tartışmaları' adı altında yürüttüğü tartışmalar, şeffaf ve herkesin katılımını öngörmesi bakımından da anlamlı bir girişimdir ("White Paper on the Future of Europe," 2017). Söz konusu tartışmaların, Beyaz Kitap'la birlikte başlayıp, 2019 Avrupa Parlamentosu seçimlerine kadar sürmesi hedeflenmiştir ("White Paper on the Future of Europe," t.y.). Avrupa'nın geleceği, yalnızca AB düzeyindeki yetkililer tarafından değil, $\mathrm{AB}$ vatandaşlarının da katılımına açı olan tartışmalar çerçevesinde belirlenmeye çalışılmıştır. Bu durumun, Birlik vatandaşlarının AB’ye bakış açılarını ve bu konudaki algılarını ne şekilde etkileyeceği de oldukça önemli bir sorudur. Avrupa Komisyonu üyeleri, Avrupa çapında seyahat ederek, vatandaşların bu beş farklı senaryoyla ilgili farklı görüşlerini dinlemiş ve bir anlamda AB’nin geleceği, vatandaşların da katılımıyla şekillendirilmeye çalışılmıştır ("A Europe That Delivers," t.y.). 2017 senesinde, Avrupa'nın geleceği üzerine yürütülen bu tartışmalarda, bin yedi yüz elliden fazla etkinliğin yapıldığı ve bu etkinliklerde iki yüz yetmiş binden fazla vatandaşın yer aldığı, bu sayıdan çok daha fazla kișinin ise söz konusu etkinliklere internet üzerinden katılım sağladığı görülmüştür ("Debate on The Future of Europe," 2017). AB'nin geleceği üzerine yürütülen tartışmalara, vatandaşların da doğrudan katılımının sağlanması hem vatandaşların söz konusu beş farklı senaryo hakkında bilgi sahibi olup, konu üzerine düşünerek fikir yürütmelerine olanak sağlamakta, hem de AB'nin demokratik işleyişini görünür kılarak, Birlik'te demokrasi açığı tartışmalarına karşı olumlu bir adım niteliği taşımaktadır.

Beyaz Kitap'ta yer alan beş farklı senaryo AB vatandaşları açısından incelenecek olursa, bu senaryoların üye ülke vatandaşları üzerinde farklı etkilerinden söz edilebilir. Bu durum, AB'nin, vatandaşlarına söz konusu senaryolarla ilgili temel ve ayrıntılı açıklamalar yapmasının önemine işaret etmektedir. Bu noktada, her bir senaryo ve bu senaryoların içinde dolaylı bir şekilde yer alan farklılaştırılmış entegrasyon modelleri, gerek Birlik vatandaşlarının bu modellere ve senaryolara yaklaşımı, gerek modellerin barındırdıkları potansiyel riskler üzerinde durmak anlamlı olacaktır. 
AB vatandaşları, 'hangi cümlenin Avrupa entegrasyonuna olan yaklaşımlarını en iyi biçimde anlattığı'yla ilgili soruyu şu şekilde yanıtlamışlardır: 'AB'de daha fazla ekonomik ve siyasi entegrasyona ihtiyaç olduğunu' düşünenler EUpinions 2021 Eylül verisine göre \%51'dir ('Eupinions Trends/Attitude,”, t.y.). 'Bugün nasılsa öyle devam edilmeli' düşüncesine sahip olanlar 2021 Eylül verisine göre \%19, 'AB'de daha az ekonomik ve siyasi entegrasyona ihtiyaç olduğunu' düşünenler ise 2021 Haziran verisine göre \%29'dur. ("Eupinions Trends/Attitude,", t.y.). Birlik vatandaşlarının AB entegrasyon sürecinin artarak devam etmesi gerektiğine dair olumlu bir yaklaşıma sahip olmaları önemlidir. Bu tablo, vatandaşların, AB'ye inandıklarını, daha fazla alanda entegrasyondan yana olduklarını göstermekte, Beyaz Kitap'ta yer alan AB'nin mevcut haliyle yoluna devam etmesini öngören ilk senaryoya ve yalnızca Tek Pazar çerçevesinde ortaklık öngören ikinci senaryoya verecekleri desteğin düşük olacağını da ortaya koymaktadır. Dördüncü senaryoyu anımsatan 'daha az siyasi ve ekonomik entegrasyon ihtiyacı' söz konusu veriler çerçevesinde ele alındığında, $A B$ vatandaşlarının çoğunluğu tarafından desteklenmeyen bir yaklaşım olacaktır.

Ülkelerinde ' $A B$ 'de kalmak ya da $A B$ 'den çlkmak üzerine referandum yapılırsa ne yönde oy kullanmayı tercih edeceklerine' ilişkin soruya 'AB'den çıkmak yönünde oy kullanırdım' cevabını verenlerin yüzdesi Eylül 2021 verisine göre \%28'dir. ("Eupinions Trends/Attitude,” t.y.) Birleşik Krallık'ın 2016 senesindeki referandumdan 2020'deki resmi çıkışına kadar AB'yle ilişkilerinin ne şekilde devam edeceğinin belirsizlik içinde sürmesi, özellikle orta ve uzun vadede meydana gelebilecek değişiklikler, olumlu ya da olumsuz gelişmelerin bilinmezliği ve AB'den çıkmanın yarar ve zararlarının net bir biçimde öngörülememesi de verilen cevaplarla bağlantılı olarak düşünülebilir. Söz konusu veriler göz önüne alındığında, $A B$ vatandaşlarının, ülkelerinin $A B$ 'de yer almasından memnun oldukları ancak işleyiște kimi değişikliklerin yapılması gerektiğini düşündükleri söylenebilir.

Bu noktada, Juncker Komisyonu'nun Beyaz Kitap'ta ele aldığı üçüncü ve beşinci senaryoları tartışmak da yerinde olacaktır. Eupinions anketinde, 'daha fazla siyasi ve ekonomik entegrasyonun gerekliliği' yönündeki olumlu cevapların oranı \%51 olup, bu durum federal bir Avrupa yaklaşımını akıllara getirmektedir. Özellikle federatif özelliklerin arttığı bir AB'de, vergilendirme, savunma gibi kimi alanlarda ortaklıklara da yer açılacaktır. AB üye ülkeleri arasında oluşturulacak olan Ortak Savunma ve Güvenlik politikasına, $A B$ vatandaşlarının \%74 gibi yüksek bir oranda destek verdikleri görülmektedir (Standard Eurobarometer 91 First Results, 2019). AB vatandaşlarının daha fazla alanda ortaklığın olduğu, daha derin bir Avrupa'ya sıcak bakıyor olmaları, federatif özelliklerin baskın olduğu bir AB'ye de sıcak baktıkları anlamına gelebileceği gibi, AB'ye ve AB politikalarına duyulan güvenin işareti olarak da yorumlanabilir. De Vries, karşılaştırma teorisinden (benchmark theory) yola çıkarak, $A B$ vatandaşlarının $A B$ 'ye olan yaklaşımlarının yalnızca $A B$ politikalarıyla ve AB'nin işleyişiyle ilgili olmadığını ileri sürerek, ulusal siyasetin etkisinden söz etmekte, bu durumun da AB'ye destek verilmesini ya da daha şüpheci yaklaşılmasını etkilediğini söylemektedir (De Vries, 2018: 23). Ulusal düzeydeki ekonomik, siyasi aksaklıklar, Birlik düzeyinde siyasi ve ekonomik entegrasyona dair bakış açısına da etki etmektedir. Ulusal düzeyde meydana gelen olumlu ya da olumsuz kimi olayların, söz konusu ülkenin AB'ye bakış açısıyla doğrudan bağlantılı olduğu vurgulanmaktadır (De Vries, 2018: 60). Diğer bir deyişle, AB üyesi olmanın avantajlı yönleri, ulusal düzeydeki ekonomik ve siyasi sorunlarla belirginleşmektedir. Bu durum, $A B$ vatandaşlarının da istek ve desteğiyle daha fazla entegrasyona ve $A B$ 'yle daha gelişmiş ilişkilere işaret edecektir. Beşinci senaryoda öngörülen ve öne çıkarılan 'daha fazla siyasi ve ekonomik entegrasyonun gerekliliği' konusuna $\mathrm{AB}$ vatandaşlarının yaklaşımı, bir anlamda belirleyici olacaktır. EUpinions verileri ele alındığında, Fransa, Almanya, İtalya, Fransa, Polonya, İspanya ve Hollanda vatandaşlarının 'Avrupa çapında daha fazla entegrasyon' düşüncesine birbirinden farklı cevaplar verdikleri görülmektedir. Eylül 2021 verisine göre Fransa \%38, Hollanda \%39 oranında diğer ülkelere göre bu konuya daha 
mesafeliyken, \%66 oranında İspanya'nın ve \%64 oranında ise İtalya'nın bu fikre en sıcak bakan ülkeler olduğu görülmektedir ("Eupinions Trends/Attitude,", t.y.). Ancak, İtalya ve İspanya, bu noktada bir bütün olarak AB'nin daha fazla entegrasyona ihtiyacı olduğu yönündeki fikre sicak bakmaktadır. Diğer bir deyişle, üçüncü senaryonun tersine, bu örnekte, kimi üye ülkelerin değil, bütün üye ülkelerin daha fazla entegrasyona ihtiyacı olduğu düşüncesi öne çıkmaktadır.

AB'de 'bütün üye ülkeler hazır olana kadar hazır olan diğer üye ülkeler de onları beklemeli' düşüncesine sıcak bakan $\mathrm{AB}$ vatandaşlarının oranı \%43 iken, 'diğer üye ülkelerinin hazır olmasını beklemeden hazır olan ülkeler yola devam etmeli' düşüncesine sahip olan AB vatandaşlarının oranı \%44'tür ("Delivering on Europe," 2018). Çok vitesli ya da iki vitesli Avrupa ile güçlendirilmiş işbirliği düşüncesine olumlu ve olumsuz bakan Birlik vatandaşları arasındaki farkın son derece az olduğu görülmektedir. Bunlara karşı olan görüş içinde (\%43) en yüksek yüzdenin Portekiz, Yunanistan ve İspanya'ya ait olması dikkate değer bir duruma işaret etmektedir ("Delivering on Europe," 2018). Sözü edilen üç ülkenin son dönemde AB'nin mücadele ettiği ekonomik krizden en çok etkilenen ülkeler olması anlamlıdır. AB vatandaşları arasında oluşması muhtemel 'birinci-sınıf' 'ikinci-sınıf' farkından en çok etkileneceği düşünülen, 'çevre' ülke olarak adlandırılan ülkeler, farklı hızlarda devam edecek bir ortaklığa olumlu bakmamaktadır. Hollanda, Almanya ve Belçika ise 'farklı hızlarda yola devam edilmeli' düşüncesinin en yüksek çıktığı üç ülkedir ("Delivering on Europe," 2018). Merkez (ya da çekirdek) Avrupa-çevre Avrupa tartışmalarında, merkez ülkeler olarak ele alınan ve özellikle ekonomik anlamda güçlü ülkelerin bu fikre daha sıcak baktığı görülmektedir. Lamers, $A B$ 'de karar-alma sürecinin de daha etkili ve demokratik olması bakımından, 'merkez' Avrupa ülkelerinin daha yakın bir işbirliği içinde olmaları gerektiğinin altını çizmektedir (Lamers, 1997: 109). Sözü edilen durum, farklılaştırılmış entegrasyonun, hukuki olarak düzenlemelerde yer almasa bile uygulanması anlamına gelmektedir. Bu durum, AB'ye ilerleme ve derinleșme adımlarında 'hız' kazandırma potansiyeline sahip olsa da, $A B$ vatandaşlarının entegrasyonu anlamında aynı hızı kazandırması şüpheli görünmektedir. Eğer AB'nin geleceği için farklılaștırılmış entegrasyon modellerinden biri ya da birkaçı öngörülüyor ve Juncker Komisyonu'nun hazırladığı beş farklı senaryo tartışılıyorsa, kuşkusuz burada en başta yapılması gerekenlerden biri, AB vatandaşlarına yapılacak yenilikler hakkında yeterli bilgi sağlanması olacaktır. 1990’lı yıllarda Maastricht Antlaşması'nın kabulü esnasında Danimarka'nın 'büyük devletlerin baskınlığının söz konusu olması' düşüncesiyle endișe yaşaması, farklılaștırılmış entegrasyona hukuki bir temel oluşturulma aşamasında $A B$ 'de yaşanması muhtemel bir durumdur. $A B$ vatandaşlarının karar-alma sürecinin nasıl şekilleneceği hakkında bilgilendirilmesi, entegrasyonun verimli bir biçimde sürmesine etki edecektir. Bu anlamda, 'Avrupa'nın geleceği üzerine tartışmalar' gibi platformların sürdürülmesinin etkili olacağı söylenebilir. AB vatandaşlarının doğrudan ya da internet üzerinden katılımına açık olan etkinliklerde yer almasıyla birlikte hem farkındalık düzeyi artacak, hem de Birlik vatandaşları AB'nin geleceğiyle ilgili alınacak kararlardaki aktörlerden olabilecektir. Farklılaştırılmış entegrasyon modellerinin içeriğinin ve uygulamasının ne şekilde olacağının ayrıntılı biçimde ele alınması ve açıklanması, hem 'birinci sınıf', 'ikinci sınıf' Avrupa endişesine cevap niteliği taşıyacak, hem de AB vatandaşlarının ne gibi değişiklikleri onayladığı ve hangilerine mesafeli durduğu ölçülebilecektir.

\section{SONUÇ}

AB'nin karşı karşıya kaldığı politik ve ekonomik krizler de göz önüne alındığında, Birlik'in geleceği için birbirinden farklı önerilerin sunulması, farklı bakış açılarının ortaya çıkması anlamlıdır. AB'nin yoluna mevcut durumunu muhafaza ederek devam etmesi, iki vitesli, a la carte, güçlendirilmiş işbirliği ve değişken geometrili Avrupa gibi Birlik'in işleyişine kimi farklılıklar getirmesi planlanan modeller, söz konusu önerilerden bazılarıdır. AB'nin geleceği için Juncker Komisyonu döneminde öne çıkan beş farklı senaryonun, sözü edilen önerilerden bağımsız olmadığı görülmektedir. Söz konusu beş farklı senaryo, AB'nin geleceği için öngörülen modellere işaret ederken, bu modellerin ve 
senaryoların her birinin Birlik vatandaşlarının AB'ye bakış açısını etkilemek anlamında farklı riskleri barındırdığı da görülmektedir. Birlik'in henüz AB adını almadığı dönemlerde 'tek bedenin herkese uyması' modelinin de barındırdığı riskler olduğu, bu modelin genişleme ve derinleşme adımlarıyla bazı noktalarda yetersiz kaldığı zaman içinde görülmüş ve bu sebepten farklılaştırılmış entegrasyon modelleri ortaya çıkmıştır. Farklı hızlarda hareket edilmesini öngören iki vitesli ya da çok vitesli Avrupa fikrinin 'birinci-sınıf' 'ikinci-sınıf' AB vatandaşı algısı yaratarak, Birlik vatandaşlarının Birlik'e entegrasyonunu olumsuz yönde etkileme olasılığı bulunmaktadır. Güçlendirilmiş işbirliği modelinde, birlik içinde küçük birlikler oluşması konusu, değişken geometrili Avrupa modelinde ise merkezçevre Avrupa algısının ortaya çıkması olasılığı, farklılaştırılmış entegrasyon modellerinin, potansiyel riskleri olarak belirmektedir. 'Avrupa'nın Geleceği Tartışmaları' gibi hem fiziksel olarak katılım sağlayabilecekleri hem de internet üzerinden takip edebilecekleri platformların varlığı, $A B$ vatandaşlarının, gelecekte nasıl bir AB hayal ettiklerini, ne şekilde işleyen bir AB'nin vatandaşı olmak istediklerini dile getirmeleri bakımından anlamlıdır. Daha verimli işleyebilecek ve temel değerlerini koruyarak bütün üye ülkelerde $\mathrm{AB}$ üyeliğini vurgulayacak bir düzenlemenin yapılması en önemli noktalardan biridir. Bu anlamda Birlik'in, üye ülke vatandaşları arasında bir ayrım yaratması muhtemel tüm önerilerden uzak durması gerekmektedir. AB vatandaşlarının, 'Avrupa'nın Geleceği Tartışmaları' benzeri platformlarda söz konusu farklılaştırılmış entegrasyon modelleri hakkında bilgi sahibi olması, AB'deki karar-alma sürecinin aktörleri olarak hangi senaryonun AB'nin geleceği için daha verimli olacağı yönünde yönlendirici olması hem AB'deki demokratik işleyiş bakımından hem de AB'nin, vatandaşlarının görüşlerini daha açık görmesi bakımından anlamlıdır. Bu tür tartışmalar sonrasında yapılacak bir kamuoyu yoklaması ise Birlik vatandaşlarının gelecekte nasıl bir $\mathrm{AB}$ görmek istediğini daha net bir biçimde ortaya koyacak, bu da AB'nin potansiyel riskleri mümkün olduğu kadar azaltarak, Birlik'in geleceğini en etkili şekilde planlamasına yardımcı olacaktır. 


\section{KAYNAKÇA}

A Europe That Delivers: Options for making the European Union's work more efficient. (t.y.). European Commission. Erişim adresi: https://ec.europa.eu/commission/sites/betapolitical/files/dialogue-with-citizens-ahead-european-elections_en.pdf.

AB Kavramları Sözlüğü. (t.y.). İktisadi Kalkınma Vakfı. Erişim adresi: https://oldweb.ikv.org.tr/sozluk.asp?bas_harf=D\&anahtar=\&sayfa=\&id=1061.

De Neve, J. (2007). The European Onion? How Differentiated Integration is Reshaping the EU? Journal of European Integration, 29 (4), 503-521.

De Vries, C.E. (2018). Euroscepticism and the Future of European Integration. Oxford: Oxford University Press.

Debate on The Future of Europe: 1,750 events so far with the potential to reach over 30 million Europeans. (2017, Temmuz 17). European Commission. Erișim adresi: https://ec.europa.eu/commission/presscorner/detail/en/IP_17_2029.

Delivering on Europe: Citizens' Views On Current And Future EU Action. (2018, Mayı). Eurobarometer Survey 89.2 of the European Parliament. Erişim adresi: https://www.europarl.europa.eu/at-your-service/files/be-

heard/eurobarometer/2018/delivering_on_europe_citizens_views_on_current_and_future_eu _action/report.pdf.

Democracy On The Move. (2018, Mayıs). Eurobarometer Survey 89.2 of the European Parliament. Erişim adresi: http://www.europarl.eu/pdf/eurobarometre/2018/oneyearbefore2019/eb89_one_year_bef ore_2019_eurobarometer_en_opt.pdf.

'Denmark rejects the Maastricht Treaty and disrupts the process of European unity' from El País (1992, Haziran 3). CVCE. Erişim adresi: https://www.cvce.eu/content/publication/2003/12/3/6516e279-9f9e-411a-98d3a2fcf9439bdb/publishable_en.pdf

Dyson, K. ve Angelos S. (2010). Differentiation as design principle and as a tool of political management in European integration. K.Dyson ve A. S. Houndmils (Ed.), Which Europe? The Politics of Differentiated Integration içinde (3-23 ss.). Basingstoke, Hamsphire; New York:Palgrave Macmillan.

Enhanced Cooperation. (t.y.). EUR-lex. Erişim adresi: https://eurlex.europa.eu/summary/glossary/enhanced_cooperation.html.

Eupinions Trends/Attitude Towards European Integration. (t.y.) BertelsmannStiftung. Erişim adresi: https://eupinions.eu/de/trends/.

Hobolt, S.B. ve De Vries, C.E. (2016). Public support for European integration. Annual Review of Political Science, 19, 413-432.

Holzinger, K. ve Schimmelfennig, F. (2012). Differentiated Integration in the European Union: Many Concepts, Sparse Theory, Few Data. Journal of European Public Policy, 19 (2), 292-305.

Kölliker, A. (2001). Bringing together or driving apart the union? Towards a theory of differentiated integration. West European Politics, 24 (4), 125-151.

Lamers, K. (1997). Strengthening the Hard Core. P. Gowan ve P. Anderson (Ed.), The Question of Europe içinde (104-116 ss.). London, New York: Verso. 
Multi-Speed $\quad$ Europe. (t.y.) EUR-lex. Erişim adresi: https://eurlex.europa.eu/summary/glossary/multispeed_europe.html

Olcay, C. A. (2007). Avrupa Birliği'nde Ekonomik ve Parasal Birlik. İçinde Ç. Erhan, A.B. Kızılırmak ve C.A. Olcay (Ed.), Avrupa Birliği: Temel Konular içinde (183-200 ss.). Ankara: İmaj Yayınevi.

Piris, J. (2012). The Future of Europe: Towards a Two-Speed EU? UK: Cambridge University Press.

Report on European Union. (1975, Aralık 29). CVCE. Erişim adresi: https://www.cvce.eu/content/publication/1997/10/13/284c9784-9bd2-472b-b704ba4bb1f3122d/publishable_en.pdf

Schmitter, P.C. ve Lefkofridi, Z. (2016). Neo-Functionalism as a Theory of Disintegration. Chinese Political Science Review, 1, 1-29.

Schramm, L. (2019). European disintegration: A new feature of EU politics. College of Europe Policy Briefs, 3(19), 1-4. Erișim adresi: https://www.coleurope.eu/system/tdf/researchpaper $/$ schramm_cepob_3-19.pdf?file=1\&type=node\&id=50743\&force $=$

Standard Eurobarometer 91 First Results. (2019). European Commission. Erişim adresi: https://ec.europa.eu/commfrontoffice/publicopinionmobile/index.cfm/ResultDoc/download /DocumentKy/88107?CFID=929869\&CFTOKEN=a9fe5185d489a568-E9D465BC-EC15-A4493B143D5F2383643C

Stubb, A. C-G. (1996). A Categorization of Differentiated Integration. Journal of Common Market Studies, 34(2), 283-295.

Teasdale, A. ve Bainbridge. T. (2012). The Penguin Companion to European Union (4. Baskı). England: Penguin Books.

White Paper On The Future of Europe: Reflections and scenarios for the EU27 by 2025. (2017, Mart 1). European Commission. Erişim adresi: https://ec.europa.eu/commission/sites/betapolitical/files/white_paper_on_the_future_of_europe_en.pdf.

White paper on the future of Europe: The way ahead. (t.y.). European Commission. Erişim adresi: https://ec.europa.eu/commission/priorities/democratic-change/future-europe/whitepaper-future-europe/white-paper-future-europe-way-ahead_en. 


\section{EXTENDED ABSTRACT}

\section{Models of Differentiated Integration and Their Effects On European Union Citizens}

The inadequacy of 'one-size-fits-all' model has become apparent in recent years and finding a new model for the European Union (EU) has become a vital issue especially after Eurozone crisis, Brexit and refugee crisis. The scenarios on the disintegration of the EU after these crises have been one of the main motivations for the discussions to find a new model. Multi-speed Europe, two-speed Europe, variable geometry Europe, enhanced cooperation and a la carte Europe are some of the models that are discussed within the framework of differentiated integration.

White Paper on the Future of Europe that released in the Juncker Commission's term presents five different scenarios for the future of the EU. These scenarios can be examined within the framework of the models of differentiated integration. These scenarios are: 'Carrying On', 'Nothing but the Single Market', 'Those Who Want More Do More', 'Doing Less More Efficiently' and 'Doing Much More Together' ("White Paper on the Future of Europe," 2017) The scenarios and models have been discussed to find the best option for the future of the EU and for EU citizens. Apparently, all the scenarios and models entail risks. One of these risks is the differences in perception of EU citizens on differentiated integration. Therefore, the new model for the EU should be considered thoroughly. Multi-speed Europe and two-speed Europe might cause misunderstandings and misperceptions such as 'first-class Europe vs. second-class Europe' and 'first-class Europeans vs. second-class Europeans'. In other words, if the speed of the EU countries is different from each other, this difference might cause divisions among Union citizens and raise question marks on the 'equality' of EU citizens. Enhanced cooperation and variable geometry also have risks. If the EU is defined as a 'group', in enhanced cooperation model, there will be subgroups in this group and this situation might bring disputes among these subgroups. In the model of variable geometry, the perception of 'core EU countries' and 'periphery EU countries' might cause a gap among member states and EU citizens. The integration of EU citizens and the construction of sense of belonging to the EU is one of the most sensitive issues of the Union so it is not possible to underestimate the role of EU citizens while constructing a new model.

In this article, models of differentiated integration will be examined with regard to five scenarios of Juncker Commission and their potential effects on EU citizens will be discussed. The data from EUpinions and Eurobarometer surveys will be used to understand the perceptions of the citizens on the issues that are related with the functioning of the EU and these issues effect on them. Their perspectives on more integration/less integration in the EU level, withdrawal from the EU/stay as a part of the EU and their attitudes towards the differentiated integration will be discussed. The perceptions and the reactions of the citizens of the Union should be one of the key determinants in this process. Especially after 1990's without the consent of EU citizens, the deepening process and the amendments in common areas have become difficult. The 'no' votes of Danish society for the ratification of Maastricht Treaty can be given as an example. The 'no' votes affected the functioning of the union and this referred to the role of the citizens in decision-making process.

While discussing new models for the EU, EU citizens should be informed about these models. Juncker Commission suggested five different scenarios for the future of Europe and 'discussions on the Future of Europe' were organized. In this way, it would be possible for EU citizens to follow up the process and get information about these scenarios. In other words, they would become the actors of these discussions to decide the future of the EU. The new model for the EU should include all EU citizens without causing any divisions among them. Therefore, taking the views of EU citizens into account and understanding their concerns to find a new model for the Union might be essential. The discussions on the future of the EU with online and/or face-to-face participation of EU citizens should 
continue while shaping the future of the EU. A referendum after these discussions might be meaningful to understand the tendencies and preferences of the citizens to find the best model for the future of the EU. 